\title{
Cerebellar Hemorrhage in a Patient during the Convalescent Phase of Dengue Fever
}

\author{
Ángel Vargas-Sánchez, ${ }^{a}$ Erwin Chiquete, ${ }^{b}$ Patricia Gutiérrez-Plascencia, ${ }^{a}$ Víctor Castañeda-Moreno, ${ }^{a}$ \\ Denisse Alfaro-Castellanos, ${ }^{a}$ Patricia Paredes-Casillas, ${ }^{c}$ José L. Ruiz-Sandoval, ${ }^{\text {a,d }}$

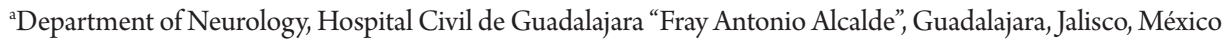 \\ bDepartment of Neurology and Psychiatry, Instituto Nacional de Ciencias Médicas y Nutrición “Salvador Zubirán”, Ciudad de México, México \\ "Department of Epidemiology, Hospital Civil de Guadalajara “Fray Antonio Alcalde”, Guadalajara, Jalisco, México \\ ${ }^{\mathrm{d}}$ Department of Neurosciences, Centro Universitario de Ciencias de la Salud (CUCS), Universidad de Guadalajara. Guadalajara, Jalisco, México
}

\section{Dear Sir:}

Dengue fever is the most common arboviral infection, accounting for an estimated 100 million cases per year worldwide and representing the most important arthropod-borne viral disease in terms of morbidity and mortality. ${ }^{1}$ This disease is principally transmitted by Aedes aegypti and Aedes albopictus mosquitoes and mainly affects populations from the tropical and subtropical regions. ${ }^{2}$ Clinical presentations of classic dengue fever include acute fever, headache, retroocular pain, skin rash, and muscular and osteoarticular pain. ${ }^{3} \mathrm{~A}$ more aggressive presentation of the illness, known as dengue hemorrhagic fever is noted in $40 \%-70 \%$ of dengue fever cases. ${ }^{4}$ Dengue hemorrhagic fever is characterized by hemorrhagic events and high fever, as well as hepatomegaly and hemodynamic alterations. Dengue shock syndrome - another clinical form of the disease-is defined as hypovolemia secondary to capillary plasma leakage with hemodynamic repercussions. ${ }^{1,4,5}$

Central nervous system complications of dengue are diverse and include acute encephalitis, acute disseminated encephalomyelitis, transverse myelitis, meningitis, cranial neuropathy, Guillain-Barré syndrome, myositis, and hemorrhagic stroke. ${ }^{1.7}$ Here, we report the case of a patient with dengue fever and cerebellar hemorrhage. A literature review was also performed to illustrate the scarcity of cases of hemorrhagic stroke in association with dengue fever.

A 64-year-old woman, with a history of hypertension under optimal control, was diagnosed with dengue fever during the
2010 outbreak in Western Mexico. ${ }^{4}$ A week after the diagnosis, a nearly complete remission of her symptoms was reported. However, 23 days after diagnosis, the patient arrived in the emergency room of our institution complaining of sudden onset headaches of moderate to severe intensity in the occipital region, vertigo, vomiting, and somnolence. A review of her vital signs showed tachypnea and blood pressure of 138/58 mmHg. During a neurological examination, the patient was found to be drowsy and dysarthric, with symmetric and hyporesponsive pupils, multidirectional nystagmus, and no papilledema. The patient was stabilized in the emergency room and a cranial computed tomography scan was performed. The scan showed cerebellar vermian and supravermian hemorrhages without ventricular drainage or mass effects over the brainstem structures (Figure 1). Magnetic resonance imaging and cerebral angiography excluded other sources of intracerebral hemorrhage, such as aneurysm, arteriovenous malformations, or dural fistulas. At this point, no hematological disturbances were noted (platelet count: 125,000/ $\mathrm{mL}$, prothrombin time: 12 seconds, partial thromboplastin time: 28 seconds, and international normalized ratio: 1.02). A serological test result for the presence of IgM dengue antibodies was reported as reactive. The patient improved within a week with conservative management, and she was discharged with minimal cerebellar deficits.

The symptoms of dengue virus infection differ in severity and characteristics, depending on the age and immunological status of the patient. The symptomatology begins after an incubation period of 3 to 14 days, with an acute febrile state that lasts about 

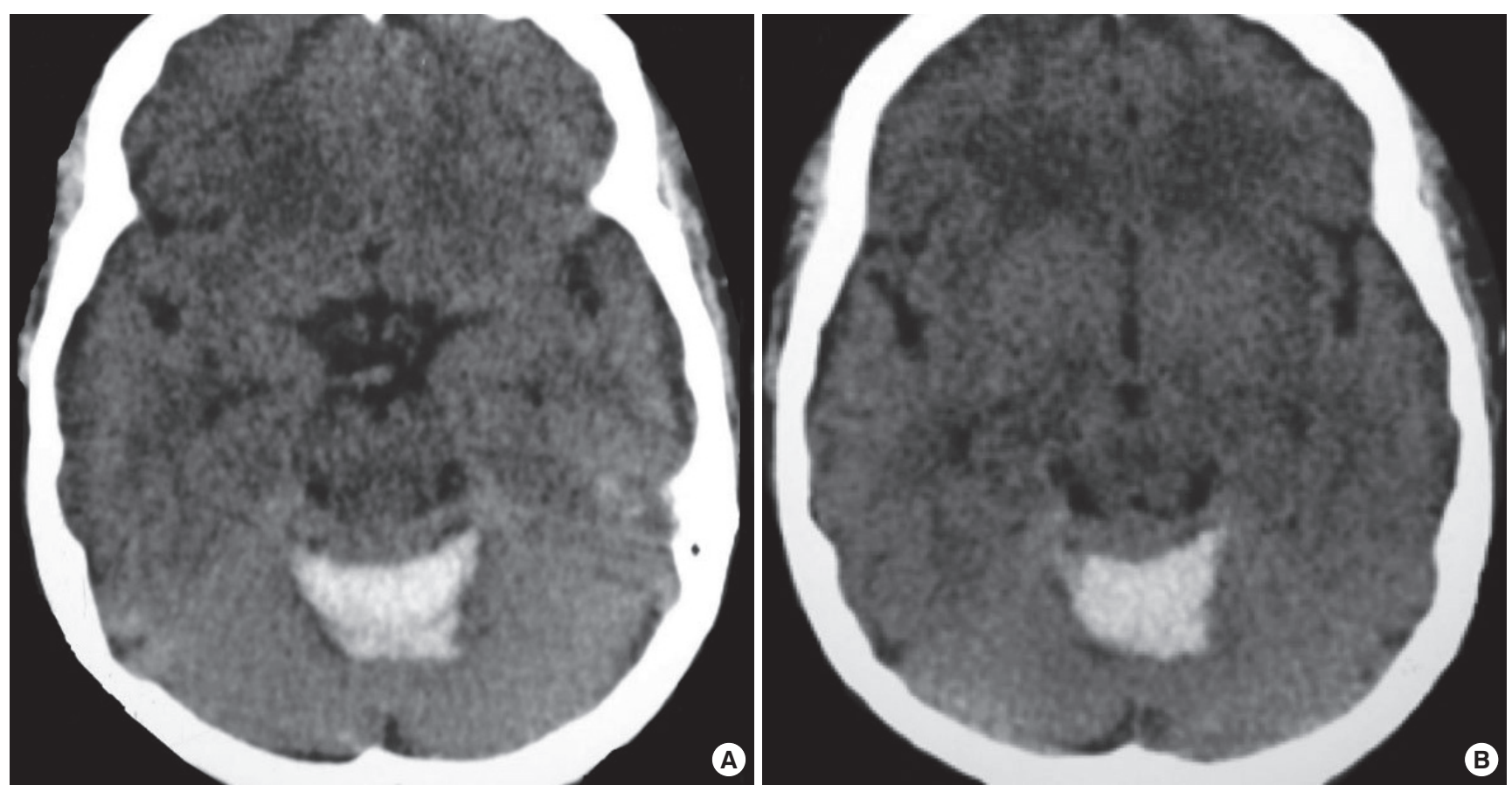

Figure 1. A computed tomography scan of the head showing a vermian (A) and supravermian (B) cerebellar hematoma.

Table 1. A literature review of reported cases of intracerebral hemorrhage associated with dengue virus infection as confirmed by serology

\begin{tabular}{|c|c|c|c|c|c|c|c|}
\hline Year/Author & $\begin{array}{l}\text { No. of } \\
\text { cases }\end{array}$ & ICH location & Age/Sex & $\begin{array}{l}\text { Time to ICH } \\
\text { presentation in } \\
\text { dengue infection }\end{array}$ & Serotype & $\begin{array}{l}\text { Platelet count per } \\
\mathrm{mL} / \text { Prothrombin } \\
\text { time }\end{array}$ & Outcome/Surgery \\
\hline 2001/Cam, et al. ${ }^{6}$ & 1 & NS & NS & NS & NS & NS & NS/NS \\
\hline 2005/De Souza, et al. ${ }^{1}$ & 1 & Pontine hematoma & 21/Female & 12th day & 3 & $95,000 /$ Normal & Improvement/No \\
\hline 2007/Kumar, et al. ${ }^{3}$ & 1 & Multiple focal parenchymal hemorrhages & 68/Female & 5th day & NS & NS*/Prolonged & Death/No \\
\hline 2009/Kumar, et al. ${ }^{2}$ & 5 & $\begin{array}{l}\text { 1. Left frontotemporal acute subdural hematoma } \\
\text { 2. Right basal ganglia hematoma } \\
\text { 3. Left basal ganglia hematoma } \\
\text { 4. Right frontal parietal acute subdural hematoma } \\
\text { 5. Left basal ganglia hematoma }\end{array}$ & $\begin{array}{c}\text { 9/Male } \\
\text { 15/Male } \\
\text { 22/Male } \\
\text { 40/Male } \\
\text { 45/Female }\end{array}$ & $\begin{array}{l}\text { 7th day } \\
5 \text { th day } \\
5 \text { th day } \\
5 \text { th day } \\
15 \text { th day }\end{array}$ & $\begin{array}{l}2 \\
2 \\
2 \\
2 \\
2\end{array}$ & $\begin{array}{l}26,000 / \text { Prolonged } \\
19,000 / \text { Prolonged } \\
\text { 39,000/Prolonged } \\
\text { 70,000/Prolonged } \\
15,000 / \text { Prolonged }\end{array}$ & $\begin{array}{l}\text { Improvement/Yes } \\
\text { Improvement/No } \\
\text { Death/No } \\
\text { Improvement/Yes } \\
\text { Death/No }\end{array}$ \\
\hline 2010/Mathew, et al. ${ }^{7}$ & 2 & $\begin{array}{l}\text { 1. Bilateral cerebellar hemorrhages and multiple } \\
\text { watershed infarcts } \\
\text { 2. Multiple hemorrhagic foci in the left parietal } \\
\text { and temporal lobes }\end{array}$ & $\begin{array}{l}\text { 35/Male } \\
\text { 45/Female }\end{array}$ & $\begin{array}{l}\text { 3th day } \\
\text { 9th day }\end{array}$ & NS & $\begin{array}{l}30,000 / \mathrm{NS}^{*} \\
75,000 / \mathrm{NS}^{*}\end{array}$ & $\begin{array}{c}\text { Improvement/Yes } \\
\text { Death/No }\end{array}$ \\
\hline 2011/Khanna, et al. ${ }^{8}$ & 1 & Right basal ganglia with intraventricular extension & 28/Male & 2nd day & NS & $5,000 /$ Normal & Death/No \\
\hline 2012/Assir, et al. ${ }^{9}$ & 1 & Right frontal lobe & 20/Male & 8th day & NS & $60,000 /$ Normal & Improvement/No \\
\hline Present case & 1 & Vermian and Supravermian hemorrhage & 64/Female & 23th day & NS & $125,000 /$ Normal & Improvement/No \\
\hline
\end{tabular}

ICH, Intracerebral hemorrhage; NS, Not specified.

a week. In severe presentations such as dengue hemorrhagic fever, increased vascular permeability, thrombocytopenia, fever, and hemorrhagic manifestations may occur, mainly between the third and seventh days of illness. ${ }^{4,5}$ Central nervous system complications associated with dengue are relatively uncommon, with a reported frequency of around $1 \% .{ }^{5}$ Cam et al. ${ }^{6}$ reported 5,400 patients with dengue fever, 27 of whom $(0.5 \%)$ presented with central nervous system involvement, but only one with an intracranial hemorrhage. Intracerebral hemorrhage associated with dengue fever is a rare condition, with less than 15 cases documented in the English literature to date (Table 1). In our review, we documented no gender differences, a wide age range at presentation, prolonged prothrombin time, and thrombocytopenia as common laboratory findings (Table 1). Kumar et al. ${ }^{2}$ reported three patients with basal ganglia hemorrhage and two with acute subdural hematoma occurring during the convalescent period of dengue fever. In all cases, prolonged prothrombin times were noted along with severe thrombocytopenia and mo- 
derate to severe headaches prior to neurological deterioration. ${ }^{2}$

The proposed mechanisms that lead to intracerebral hemorrhage in dengue infections are mostly related to impaired hemostasis: thrombocytopenia, prolonged clotting times with or without disseminated intravascular coagulation, or multiple organ failure and capillary leakage syndrome. Other associated conditions might include direct tissue lesions (encephalitis), vasculopathy, cerebral hypoxia, fluid and electrolyte disturbances, and hepatic and/or renal failure. ${ }^{5,6}$ A possible cause of the hemorrhage in our patient could be inflammatory vasculopathy. Vessel function is a part of the hemostasis mechanism that has been implicated in the pathogenesis of dengue fever, even in the absence of altered coagulation or platelet count. ${ }^{5,6}$ In this case, we discarded a hypertensive etiology since the hematoma location was not typical of hypertensive intracerebral hemorrhage, and the blood pressure was always normal and well controlled. However, we cannot exclude that platelet function, rather than count, other non-discernible coagulation disturbances, or chronic vasculopathy associated with hypertension could be a predisposing factor in this case.

Our case illustrates a rare complication of dengue fever, especially because it presented during the convalescent phase of the disease, and without any identifiable association with coagulopathy. Although this issue may be subject to reporting bias, to the best of our knowledge, this case represents the thirteenth reported in the medical literature (Table 1), and the only case with normal coagulation and platelet counts presenting in the convalescent phase of the arboviral infection. When other major causes have been ruled out and before classifying the intracranial hemorrhage as idiopathic, dengue virus infection should be considered in the differential diagnosis in endemic areas or during outbreaks.

\section{Acknowledgments}

The authors declare that there are no conflicts of interest. This report was received, reviewed, and approved by the Committee of Ethics of the Hospital Civil de Guadalajara "Fray Antonio Alcalde."

\section{References}

1. De Souza LJ, Martins AL, Paravidini PC, Nogueira RM, Gicovate Neto $\mathrm{C}$, et al. Hemorrhagic encephalopathy in dengue shock syndrome: a case report. Braz J Infect Dis 2005;9:257-261.

2. Kumar R, Prakash O, Sharma BS. Intracranial hemorrhage in dengue fever: management and outcome. A series of 5 cases and review of the literature. Surg Neurol 2009; 72:429-433.

3. Kumar J, Kumar A, Gupta S, Jain D. Dengue hemorrhagic fever: an unusual cause of intracranial hemorrhage. J Neurol Neurosurg Psychiatry 2007; 78:253.

4. Fajardo-Dolci G, Meljem-Moctezuma J, Vicente-González E, Venegas-Páez FV, Mazón-González B, Aguirre-Gas HG. Dengue fever in Mexico. Knowledge for improving the quality of health. Rev Med Inst Mex Seguro Soc 2012;50:631-639.

5. Puccioni-Sohler M, Orsini M, Soares CN. Dengue: a new challenge for neurology. Neurol Int 2012;4:e15.

6. Cam BV, Fonsmark L, Hue NB, Phuong NT, Poulsen A, Heegaard ED. Prospective case-control study of encephalopathy in children with dengue hemorrhagic fever. Am J Trop Med Hyg 2001;65:848-851.

7. Mathew S, Pandian SD. Stroke in patients with dengue. J Stroke Cerebrovasc Dis 2010;19:253-256.

8. Khanna A, Atam V, Gupta A. A case of dengue encephalitis with intracerebral hemorrhage. J Glob Infect Dis 2011;3:206-207.

9. Assir MZ, Jawa A, Ahmed HI. Expanded dengue syndrome: subacute thyroiditis and intracerebral hemorrhage. BMC Infect Dis 2012;12:240.

Correspondence: José L. Ruiz-Sandoval

Servicio de Neurología, Hospital Civil de Guadalajara "Fray Antonio Alcalde", Hospital 278, Guadalajara, Jalisco 44280, México

Tel: +52-33-3613-4016

Fax: +52-33-3614-1121

E-mail: jorulej-1nj@prodigy.net.mx

Received: March 5, 2014

Revised: August 15, 2014

Accepted: September 7, 2014

The authors have no financial conflicts of interest. 